\section{Projecting architecture:}

increasing the concepts of reality.

A contemporary review on the criticism considerations on the Wittgenstein house

\section{| RESUMEN |}

El carácter áulico de las grandes obras, o la permanencia en un tiempo más amplio que el de la vida humana han atraído al ser humano desde tiempos sin registro. No supondría mayor novedad el que un filósofo se interesara en una vivienda que su hermana deseaba construirse, en el tiempo germinal del Movimiento Moderno. Una casa que no es solo un proyecto de arquitectura, sino un instrumento de investigación que enriquece la percepción que de la realidad tenía Wittgenstein.

\section{| ABSTRACT |}

The courtly character of the great buildings or their permanence, as opposed to the short human life, has attached people since time began. It would not be unusual to hear of a philosopher, being interested in a house his sister wanted to build, in the seeds of foundation of the Modern Movement. The house is seen not only as an architectural project, but as an investigation method that enriches the perception of reality that Wittgenstein had.

\title{
Proyectar arquitectura: aumentar la noción de realidad Un redescubrimiento contemporáneo desde la crítica
posmoderna de la casa Wittgenstein
}

a casa que el filósofo Ludwig Wittgenstein Llevantaba para su hermana entre 1926 y 1929 en la Viena postimperial nos es más conocida por la confrontación interpretativa sobre la misma que por la casa en sí, bastante desconocida, de hecho. Entre la casa ideal-que contuviera un espacio ideado para pensar-que un catedrático de Cambridge levantaba para su hermana en un claro de bosque en Corrección de Thomas Bernhard, y la casa que con sus formas cúbicas sustraídas parece un cajón vacío describía Claudio Magris en su viaje por el Danubio, se ha generado una imagen idealizada de casa inhabitable, en el límite entre una verdadera casa y la imposibilidad de la misma. Esta casa se nos ha presentado enconadamente por gran parte de la crítica desde la formatividad física de la misma, según los rígidos principios de un discurso estructuralista; la casa ha sido y es leída como lógica encarnada en casa -según las propias palabras de su propietaria- un intento de dotar de orden metalingüístico al elenco material y técnico que es un proyecto de arquitectura.

\begin{abstract}
Despiertan nuestro interés los personajes concretos, estando la autoría atribuida al filósofo Ludwig Wittgenstein, el filósofo de la lógica metaenunciada del TRACTATUS LOGICO PHILOSOPHICUS, amigo íntimo de Adolf Loos; y siendo la propietaria su hermana, Margaret Stonborough-Wittgenstein, una de las mecenas más solicitadas de la cultura vienesa de la época. Es esta coincidencia en espacio y tiempo con aquel INTERNATIONAL STYLE lo que ha forzado su denuesto por la crítica posmoderna, al asimilarla a un enunciado radical de aquellos principios de la modernidad más severamente sojuzgados por esta. Es también objeto intemporal de fascinación de arquitectos que la conocen desde algunas lecturas transversales, que asimilan la casa a monumento heroico del arquitecto creador que busca imponer su verdad contra la del mundo. En todo caso, esta literalidad de la casa como construcción física de la filosofía primera de Wittgenstein ha sido afirmada y negada simultáneamente por la crítica ${ }^{[1]}$, pero existe una evidente correlación entre el esfuerzo sintético de la estructura enunciativa del TRACTATUS y la reducida formalización del palais.
\end{abstract}

Juan D. López-Arquillo, doctor arquitecto y urbanista. Director del estudio LAA arquitectura e Ingeniería. Profesor de Imagen Urbana, CCUCP, Universidad de Granada (laa.arquitectos@gmail.com).

[1] De hecho, las interpretaciones más abundantes dentro de la crítica sobre la casa, tan multidisciplinar, son aquellas que explican la casa como una transducción literal mediante representación de una serie de enunciados del TRACTATUS LOGICO PHILOSOPHICUS. Destacan las lecturas de Otl Aicher al respecto. 
1. Situación en plena Kundmangasse, junto al Danubio y junto a la Beatrixgasse (Cortesía archivo TUW).
2. Primer croquis del proyecto inicial de Engelmann, marzo 1926 (Cortesía Bundesdenkmalan y Pierre Stonborough).
3. Croquis del proyecto del Engelmann abril 1926, antes de participar Wittgenstein (Cortesía Bundesdenkmalan y Pierre Stonborough).

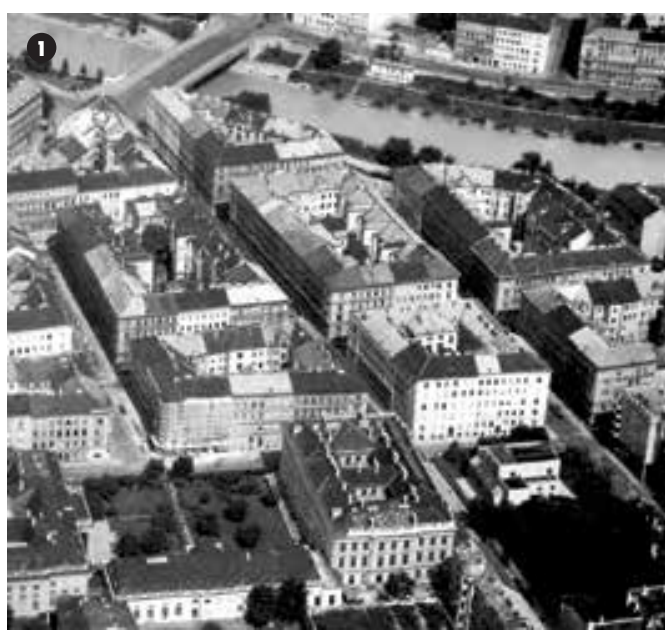

La delgada línea que separa el vacío de las arquitecturas representativas de la imposibilidad de lo meramente doméstico, queda aparentemente plasmada en este proyecto mediante la traducción físico-geométrica del complejísimo enunciado de la noción de realidad, explicitada secuencialmente por Ludwig Wittgenstein en el incomprendido TRACTACTUS Logico Philosophicus. Esta serie de aseveraciones secuenciales ${ }^{[2]}$ se proyectan aparentemente en esta casa mediante unos principios compositivos muy similares a los iniciales del Movimiento Moderno: la arquitectura como volumen, predominio de la regularidad en la composición, y ausencia de decoración añadida. Estas evidencias superficiales han provocado la acusación posmoderna del origen moderno del palais. Sin embargo, una vez experimentada la casa, el reduccionismo global del proyecto es superado por la vivencia atmosférica y elemental de sus espacios, inaugurando un goce fenomenológico en el habitar espacial y temporal mayoritariamente obviado por la crítica, pero que es evidente en la casa, ahora que volvemos a mirarla desde la hermenéutica de la anulación contemporánea de categorías del estilo.
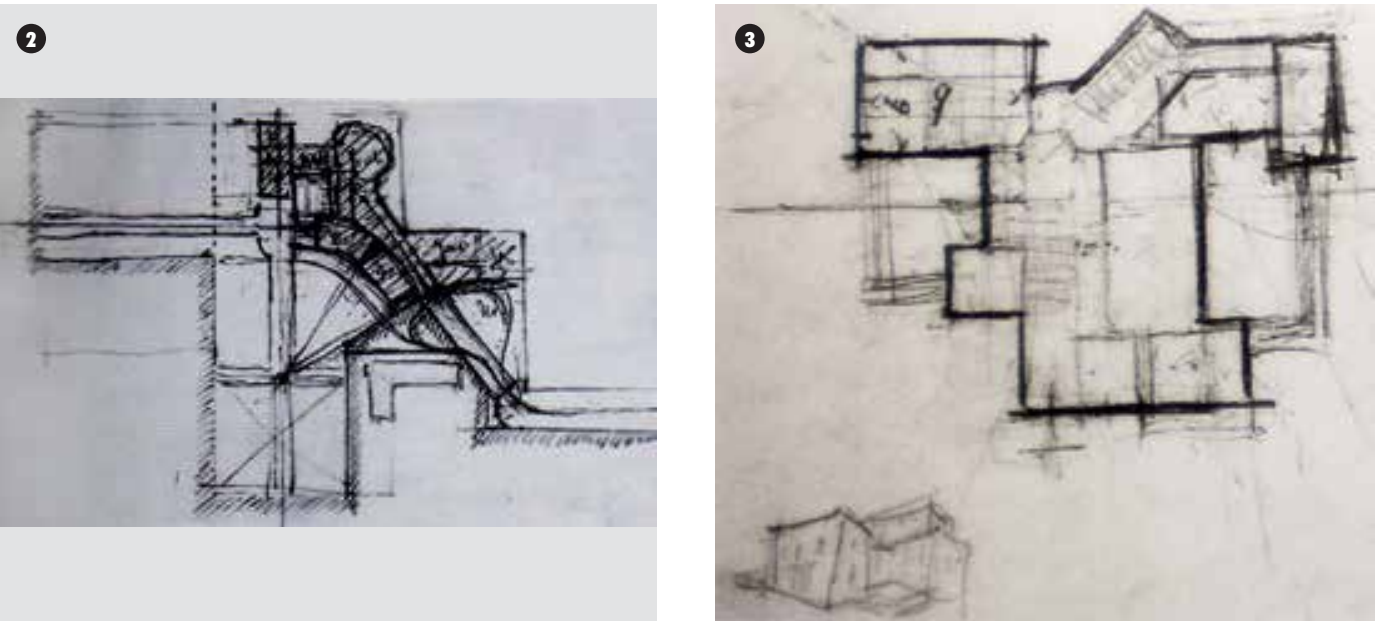

Entre la arquitectura áulica de Palladio, que se erige más allá del programa residencial, y las pseudoarquitecturas residenciales que se levantan -en todas nuestras ciudades- sin otra excusa que una necesidad de alojamiento, la historiografía define varias series de grandes obras de arquitectura, a caballo entre la eternidad de los vacios inhabitables y la futilidad de los programas domésticos estándares; pero la indefinición de la interpretación asociada a las funciones en la ciudad física y digital -real y virtual-que hoy habitamos, pone en entredicho esta categorización. Desde ella nos acercamos.

El proyecto comienza con el encargo, en la
Navidad de 1925, de un nuevo palacete,
por parte de Margaret Stonborough-
Wittgenstein, hermana de Ludwig Wittgenstein
(el filósofo, antes ingeniero mecánico) y de
Paul Wittgenstein (el pianista) y que, a la
postre, era una de las mayores mecenas de
la maltrecha Viena del pospacto de Versalles.
Originalmente ubicado el proyecto dentro del
Ring vienés y en un patio interior de manzana,
fue iniciado por Paul Engelmann, arquitecto
discípulo de Adolf Loos y que había además
colaborado con él en el proyecto de la Villa en

el Lido de Venecia (1923). Engelmann inicia una intensa labor, entre los primeros días de 1926 y mayo de aquel año, comenzando por un palacete desubicado, de corte palladiana, muy en el recorte de las villas wagnerianas que proliferaron en la Viena de cuarenta años atrás $s^{[3]}$. Engelmann, hasta entonces asumiría la ardua tarea de evolucionar un profuso proyecto inicial muy apartado de las necesidades que, cambiando, fundarían el proyecto finalmente desarrollado. El arquitecto asume un proceso de proyecto, entre el encargo en enero de 1926 y mayo de ese mismo año, en el que asume el error de decisiones de la propiedad y que, sobre todo, fija las trazas de una geometría clásica deformada por las codificaciones sociales asociadas a los diferentes interiores.

En un momento, tras varios meses, en el que trabaja sobre una evolucionada versión de la planta-ciertamente clasicista- Ludwig Wittgenstein irrumpe en el proceso, se autotitula arquitecto y comienza a modificar la planta pero respetando sus trazas fundamentales, según una visión previa de búsqueda de proporciones solo dedicado a la reforma de interiores ${ }^{[4]}$,

2] Con unas evidentes lecturas desde la formatividad de procesos físicos.

[3] Durante los años de estudio con Loos, Engelmann realizaba estudios sobre las villas que K.F Schinkel y Otto Wagner realizaban en Berlín y Viena. En una publicación de la escuela de Arquitectura que Loos fundó en Viena, Engelmann hacía un proyecto de una villa «tipo», según las que Wagner había realizado siguiendo los cortes de Schinkel.

[4] Margaret había vivido durante años en su apartamento de Berlín, reformado íntegramente por Joseph Hofmann en 1905 
4. Planos superpuestos del proyecto de Engelmann y del proyecto final conjunto Engelmann y Wittgenstein, navidad de 1926 (Del autor).
5. Plano definitivo de la planta baja, con relación constructiva, noviembre 1926 (Cortesía Baupolizei Viena).
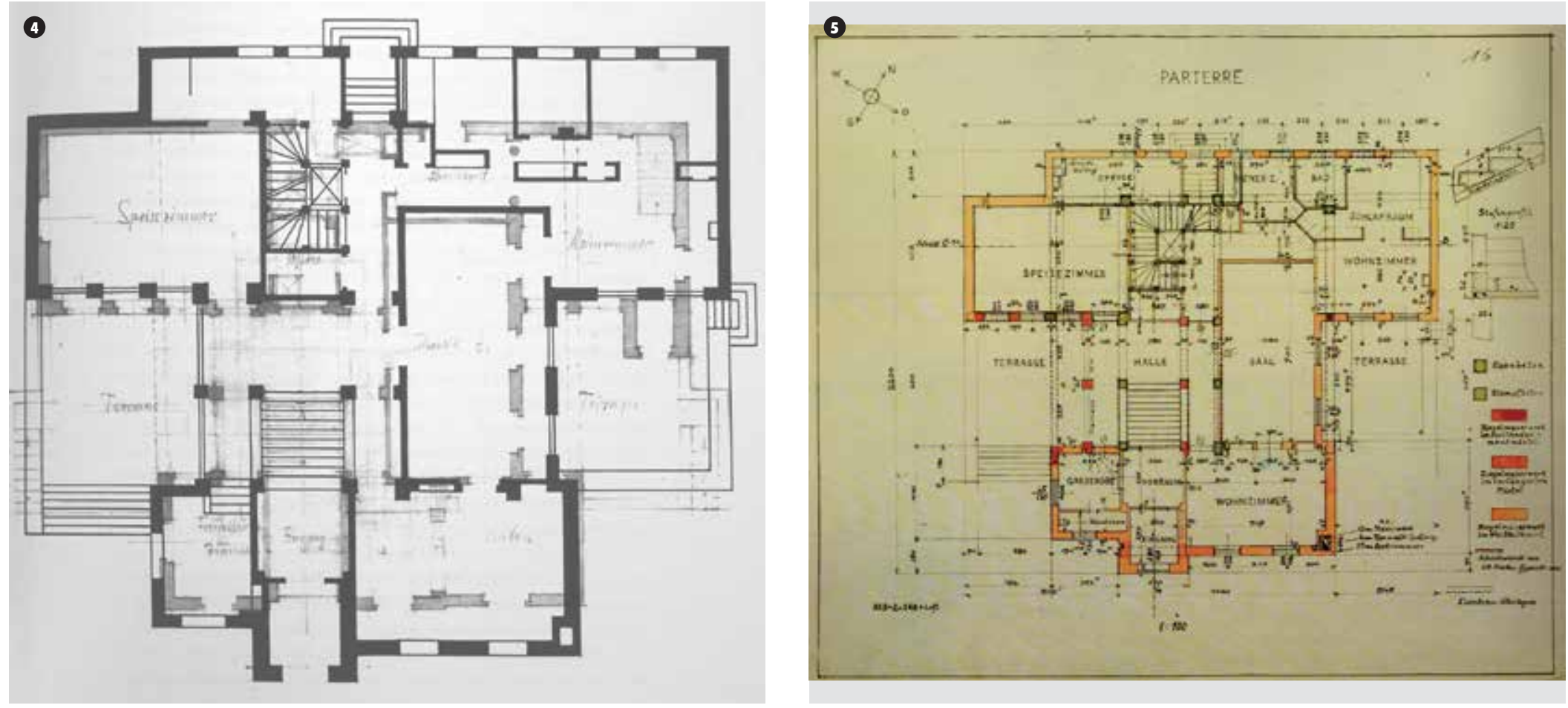

puras en sus espacios y volúmenes. Será por tanto Ludwig Wittgenstein el que acabe el proyecto ante un Engelmann retrotraído, y se hará cargo tanto de la búsqueda de un nuevo solar en el extrarradio, como del posterior proceso de obra. Esta fijación de una planta ya grafiada por Engelmann en el momento de proceso en el que aparece Wittgenstein, implica una eliminación de otras opciones de planta que ahorra a Wittgenstein el ingente trabajo de tomar decisiones desde un punto inicial, que por amplio implica el más rico momento del proyecto de arquitectura pero, por ello mismo, el más frágil y tendencioso. Finalmente, Engelmann admitiría más allá de 1935 que «él fue el arquitecto, no yo, y aunque los rasgos principales de la planta de la casa estaban ya hechos antes de que él se sumara al proyecto, considero que el resultado final es un logro suyo y no míos ${ }^{[5]}$.
Wittgenstein comienza a trabajar a finales de mayo de 1926 sobre la séptima fase de proyecto de Engelmann, dibujando detalles sobre ella, y una vez redibujada y adaptada surge un dibujo que denota la reducción formal y decorativa; lo concreto aparece como el único punto de densidad en el que la intencionalidad de autor puede aparecer en esta casa. Relata su hermana que: «Ludwig diseñó cada ventana y cada puerta, cada cierre de ventana y cada radiador, con tal cuidado y atención al detalle que pudieren pasar como elementos de precisión, y a la vez de forma sumamente elegante. Y entonces, con su inagotable energía, se aseguraba que todo se realizara con el mismo y meticuloso cuidado» ${ }^{[6]}$. Puesto que la traza fundamental, la geometría de base ya estaba solucionada por Engelmann, Wittgenstein puede desarrollar su actividad proyectiva concentrándose en los detalles; que suponen el incremento de ruido intencionado en la casa, un margen de libertad creativa en el que la marca personal del autor puede permanecer.

Habiendo descubierto Wittgenstein esta vocación de trabajo sobre esos encuentros entre sistemas, lleva la definición, supervisión y conformación del trayecto de la realidad gráfica a la física como el verdadero significado de la dirección de obra. Con la creencia en la capacidad de la técnica para modificar la realidad, Wittgenstein define la composición y el dibujo como algo primordial no solo como representación de una realidad externa, sino porque es posible de una perfecta exactitud, en sí mismo y respecto a su función, y por ello el proyecto de noviembre de 1926, antes de iniciar la obra física, muestra una definición ingenieril de los diversos sistemas de la edificación, sin concesión a la belleza gráfica de las definiciones académicas del Beaux arts, desde la que pretendía expresarse Engelmann. La belleza para el Wittgenstein del TRACTATUs era algo inalcanzable, pero para el Ludwig que opera a modo de arquitecto, como ingeniero, es la expresión del perfecto ajuste

[5] En una carta del mismo Engelmann a Margaret Stonborough-Wittgenstein

[6] En los DiarIOS DE FAMILIA de Hermine Wittgenstein. 
6. Plantas de los proyectos de Engelmann hasta 1935 a escala similar: Villa Muller, estudio de Villa, casa Konstand, casa Kellor, casa Lier y Palais Wittgenstein (en rojo) (Del autor)
7. Planta de localización, 1928

(Cortesía Baupolizei Viena).
8. Esquema estructural (Del autor).

\section{○}

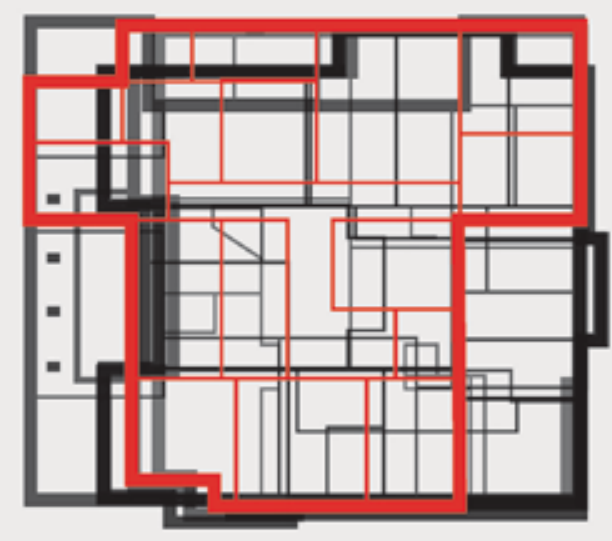

entre su funcionalidad y su estructura interna, una coherencia entre la potencialidad de su función y la forma de su organismo interno.

Las consideraciones sobre la representación cambian radicalmente entre el TRACTATUS y las investigaciones posteriores ${ }^{[7]}$. Todo queda desecho por la experiencia de los planos de la casa. Wittgenstein había tratado de desarrollar sobre el trabajo de Engelmann -fehacientemente academicista- un dibujo objetivo, descriptivo y sin un valor añadido sobre la plasmación de la realidad de lo que sería la posterior obra de edificación. Los planos de la casa antes del inicio de obra son planos técnicos, objetivos, descriptivos. Sin embargo, en la construcción de la misma descubre una representación en dos fases, en la que la figura externa -el significante, el dibujo- no ha cambiado, lo que ha cambiado es la segunda fase -el significado, la imagen interna percibida- por lo que admite finalmente que nuestros datos sensoriales alteran la representación del objeto por cuanto depende de nuestra percepción. Esta secuencia de descubrimientos realizados en el trayecto formal del papel a la obra conduciría al Wittgenstein del Tractatus al enunciado de un germen de la

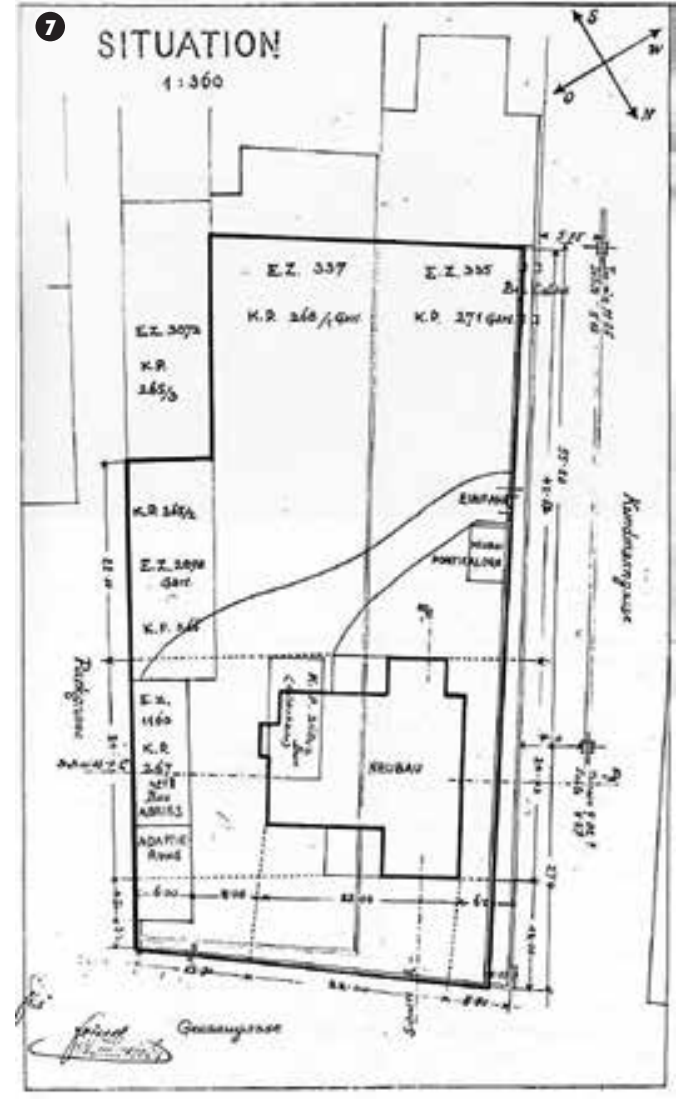

teoría de la experiencia sensorio-intelectual, noción fenomenológica de que los objetos de nuestra experiencia inmediata son las entidades indefinidas y privadas; lo que los perceptólogos como Merleau-Ponty llamarán datos sensoriales, fundando la experiencia del habitar que facilitaría, años más tarde, a la superación misma del propio Movimiento Moderno.

El proyecto academicista de Engelmann sobre el que se efectúan las transformaciones sucesivas de Wittgenstein -que posibilitaba acortar lo que a Wittgenstein le hubiera resultado un eterno ciclo de toma de decisiones sin final posible- hacen que la arquitectura de la casa permanezca actualizada permanentemente por

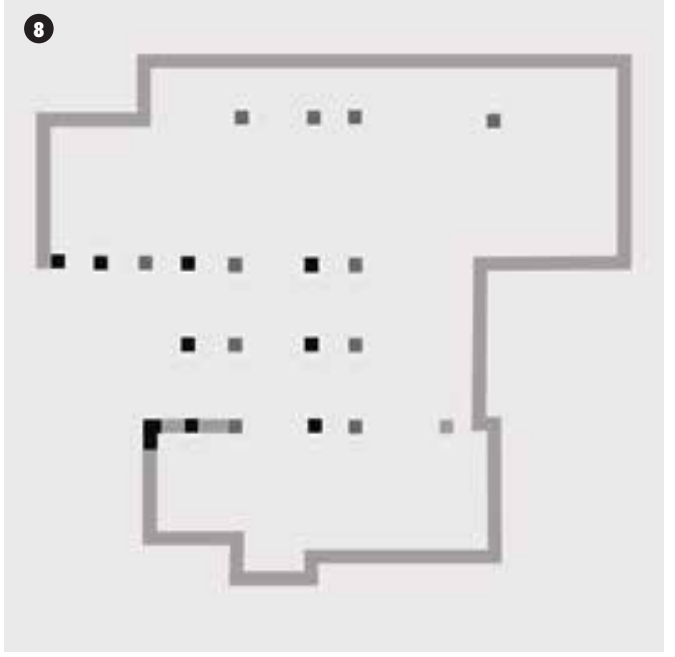

su fijación en el tipo arquitectónico: al igual que La Tourette permanece en el tiempo al asociarse a un tipo histórico que Ronchamp desautoriza, la casa se construye sobre mecanismos de la arquitectura más allá de expresiones temporales: simetrías, material, estructura, función adaptable y escalada en sí misma, con una atención al detalle netamente posmoderna y constructivamente eficaz. Es por ello que el orden estructural se convierte en uno de los principales medios de abstracción visual y material en la casa, pues la negación del capitel - o su reducción a un ábaco lineal que opera en la reducción del encuentro entre equino y arquitrabe- y la ausencia de basa, es el rasgo primero de una estructura física que se muestra de forma parcial en la casa, que formaliza el espacio mediante la ruptura de la tenue y plana luz vienesa.

La casa Wittgenstein está evidentemente ligada formalmente al carácter Mediterráneo del que se acusaba a los proyectos domésticos ${ }^{[8]}$ de Adolf Loos. La luz es difusa y tenue, con un componente de temperatura solar que la hace casi blanca, incluso cuando el Sol se ubica hacia el Sur. En la transición entre interior y exterior 
9. Perspectiva desde el jardín, 1929. Autor: Moritz Nahr (Cortesía archivo TUW).

descubrimos toda una secuencia de conexiones visuales y de acceso que nos hacen establecer una relación inmediata por la conformación de sus cerramientos como láminas genéricas sin grosor mostrado, que hace contactar directamente interior y exterior sin mayor mediación que los $40 \mathrm{~cm}$ de ladrillo macizo revestido por ambas caras con el mismo revoco a la cal, que provoca el fracaso higrotérmico que hace la casa inhabitable en ciertas épocas. En los alzados, la adopción de proporciones historicistas en los huecos -no dejan de ser verticales y superpuestos en vertical-afirma en la casa la superposición de órdenes mediante la adopción de presencias simultáneas en el interior: las dobles carpinterías a haces interiores y exteriores niegan la presencia del espesor murario, evitando la protección de un sol que evidencia el origen y el fin de una arquitectura doméstica al servicio del hombre.

La forma de la arquitectura de Wittgenstein surge de forzar el material hasta el extremo conceptual que llega a expresar una configuración material. Esta es la vía por la que lo realmente excepcional emerge en la casa. La dimensión real de los elementos estructurales necesarios para el comportamiento mecánico no se percibe, pues su presencia imbuida en paramentos y superficies y los elementos falsos incorporados en su misma jerarquía evidencian un papel presente de la estructura, pero misteriosamente desvanecido por un tratamiento espacial pretendidamente unitario. El espacio queda formalizado en hormigón armado in situ -para forjados y vigas-y con hormigón pulido, muros de ladrillo revestidos y hormigón prefabricado para el resto.

Todo queda superpuesto en un conjunto tectónico que, sin embargo, se hace homogéneo con la sencilla disposición de un bruñido, interior y exterior, de estuco a la cal. Esta incoherencia entre lo que hay y lo que se percibe pone de relieve cómo Wittgenstein veía la edificación,

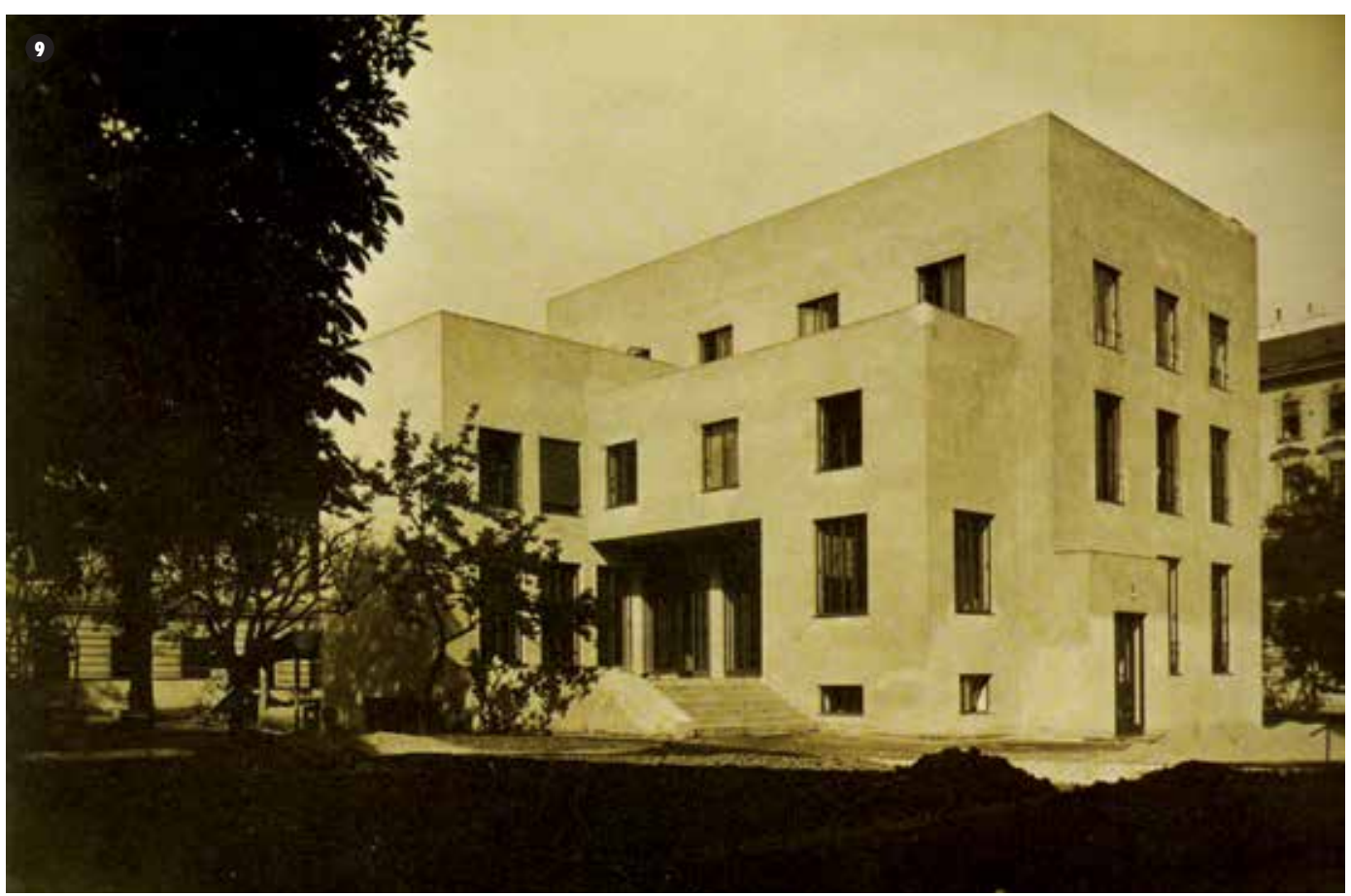

como un acto muy superior a la mera colocación en vertical de material según un orden prefijado o estructuralmente comprobado. No concebía que la obra de la casa se realizara con materiales amorfos o elementos manuales, pues esa indefinición no era mediada por un proceso industrial que lo dotara de precisión y medida, aunque todo se dejara en manos no cualificadas de obreros ${ }^{[9]}$. Sin embargo, la integridad de la obra física más allá de la limpia superficie parece resultarle indiferente, aunque nos relata también su hermana que cuando el último cerrajero que participó en la obra le preguntaba por primera vez:

«Dígame, Lieuteniant Ingenieur, żrealmente importa tanto un milímetro aquí o allí?», Wittgenstein gritó sobresaltado: iiSí!! ${ }^{[10]}$.

Estos milímetros interiores no promulgan una estricta precisión del volumen exterior, pues la superposición en vertical de las diferentes plantas de la casa responde no solo a la relativa falta de espacio en la parcela, sino que es un elegido mecanismo de acumulación en vertical para posibilitar la pretendida escala palaciega, dotando de una dimensión vertical reconocible a la pequeña pieza doméstica ${ }^{[1]}$. La unidad abstracta del volumen exterior no se corresponde con la radical segregación de usos y funciones de plantas, pues la planta primera y segunda se destinan a dormitorios y despachos, mientras que el semisótano es un movimiento inevitable para separar la casa del frío suelo artificial generado mediante el relleno de parte de ese plinto que la separa de la ciudad, a modo de un ciclópeo bathron de las fortificaciones clásicas.

La casa es más que una vivienda un proyecto urbano, pues aprovechando un promontorio existente en el solar se genera un estilóbato orográfico para todo el conjunto, una suerte de

\footnotetext{
[9] Clases bajas a las que detestaba desde la experiencia con los soldados en la Guerra, no por razones económicas sino de honor, pero a los que intentaba, sin embargo, adoctrinar.

[10] Hermine Wittgenstein, op. cit.

[11] La ubicación original del palais, en el interior de una manzana, era del desagrado del marido de Margaret, pues la casa no se vería desde la calle.
} 
10. Interior, hall, 1929. Autor: Moritz Nahr (Cortesía archivo TUW)
11. Interior, hall, actual (Del autor).

12. Interior, sala de música, 1930 (Cortesía archivo TUW).

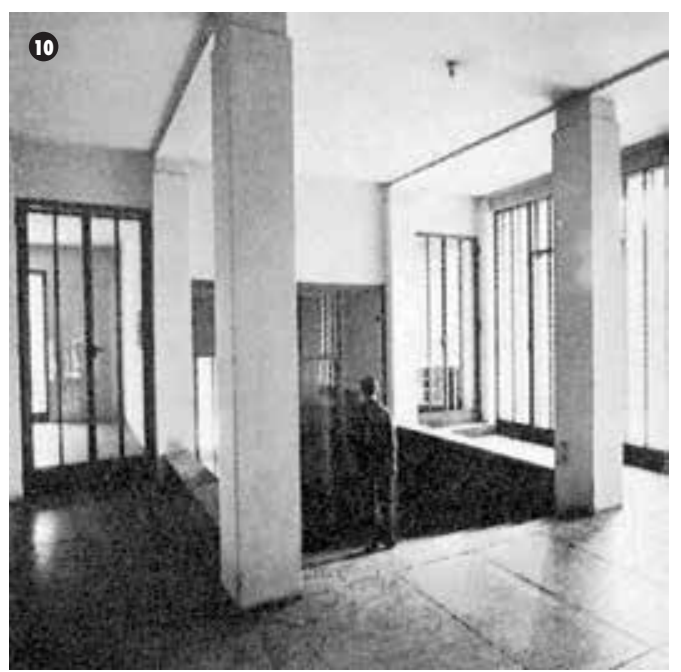

jardín-plataforma que a modo de plinto sostiene la casa fuera de la ciudad, introduciendo en la calle un incremento diferencial de artificialidad, una reproducción de naturaleza ajardinada rural que nunca existió en el lugar, fundando la casa y la plataforma como un organismo complejo apartado de la secuencia parcelaciónurbanización-edificación que fundará la morfología edilicia de tantas ciudades, como resultado de aplicaciones legales de ordenanzas poco meritorias. La vivienda se tercia en ampliada actualización de un tipo histórico, el de villa rural -que la hace estar permanentemente actualizada- pero pese a ese carácter completamente autónomo es, a la vez, completamente sensible al mismo y a sus cualidades ciudadanas y orográficas. El volumen principal de la vivienda se asienta en el lugar, por tanto, mediante una actuación estereotómica comedida que adapta el terreno existente, realineando las cotas y creando una plataforma sobre la ciudad que posibilita la impronta que el palais tiene en su entorno próximo, mostrándose como una pieza contradictoriamente bien insertada dentro del mismo.

El volumen principal queda colocado en el fondo de la parcela, protegida del barrio por el gran jardín sobre el que se coloca, elevado, en su parte frontal. El jardín no es tal, sino que queda constituido como transmutación del vallado en muro de contención del relleno
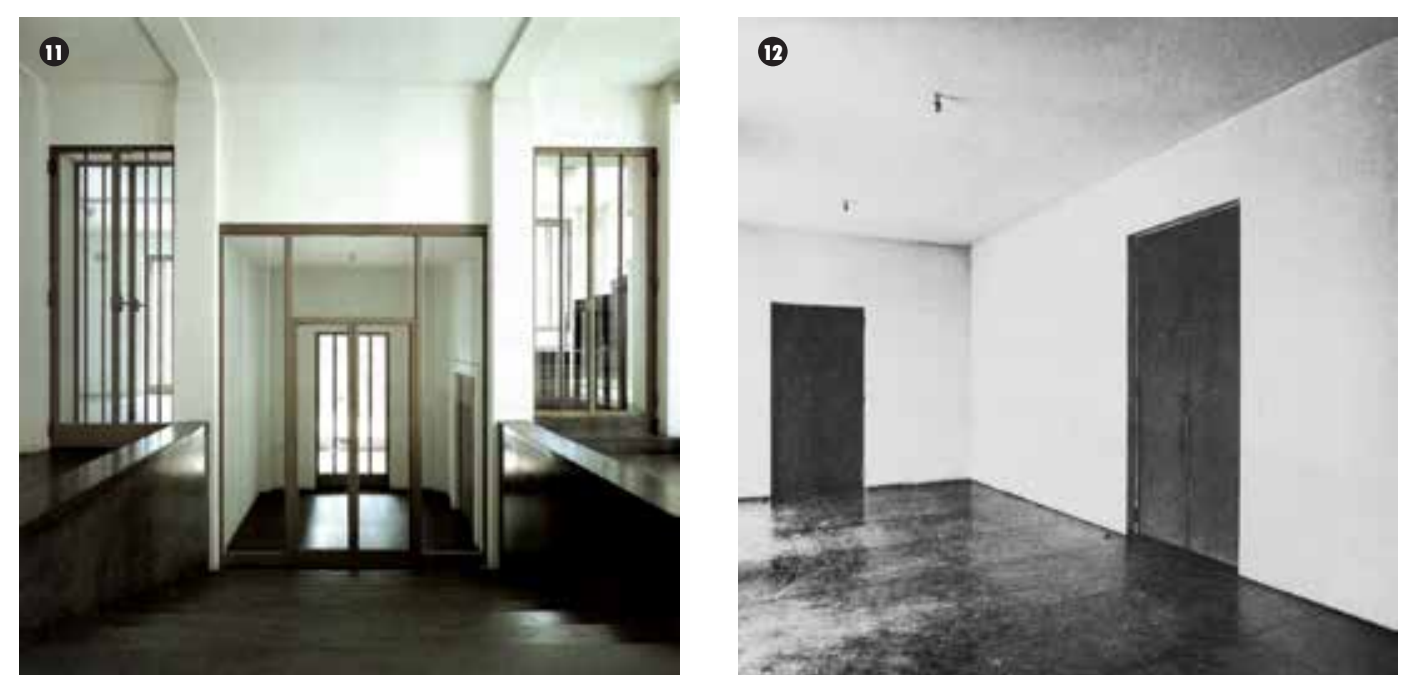

interior de la parcela, lo que permitía ganar toda la superficie útil de la parcela para jardín, dado que almacenes, cocheras y servicio quedaba a nivel de calle, pero bajo el jardín. Aún hoy, queda protegida de su entorno de alta manzanas de vidrio por este plinto sencillo que a modo de plataforma separa la casa de una realidad de la que huye virtualmente. Esta relación con lo cercano no la provoca el lugar, pues es recreada aquí, como podría en cualquier otro lugar. Este no-lugar artificial ofrece una oportunidad inocua; es específica sin lugar, porque la única referencia a su calidad es ella misma y su proceso. Bien podría estar en cualquier otro lugar. La conformación del conjunto del palais, por su abstracción y sustracción de la disciplina de la época, intenta quedar apartado de las clasificatorias de la naturaleza y de la ciudad. Se podría establecer que la vivienda y el podio -plinto- poseen cualidades tectónicas opuestas, pues tal y como establece Semper con sus términos de earthwork y roofwork, casa y plinto formarían unidades diferentes.

Según esta dicotomía han sido explicitados por pocos autores, aunque queda claro que tanto vivienda como podio son igualmente artificiales y se realizan desde la acumulación vertical de material, no desde la excavación. Ambos son tectónicos y estereotómicos a la vez, como se refrenda a nivel estructural y material, pues
Ileno y vacío son operaciones complementarias en esta operación de desnudez progresiva del material. Tanto es así, que el sótano de la casa se encuentra sobre la rasante de la calle.

La escala triunfal con la que se percibe la casa al acceder a ella se logra mediante una coincidencia visual; el suelo de la planta baja y el suelo del jardín se encuentran separados a una altura equivalente a la línea de visión, desde la entrada la planta principal es un plano fugado inalcanzable en su fin. Existe otro plano virtual que sostiene la operación urbana; y un plano formado por la cota del jardín y la altura del antepecho que limita el jardín y que sostiene la visión de la ciudad. El horizonte próximo de la planta baja queda establecido como un plano conceptual ubicado en paralelo al horizonte próximo que soporta la visión de la ciudad, quedando así percibido el exterior desde el interior de la planta baja como un juego pictórico de realidades elevadas una sobre otra, una inestabilidad de niveles generada por la multiplicidad de los mismos, que hace que perdamos la noción de la altura base $^{[12]}$. Debido a esta inestabilidad visual y

[12] Hay tantos pasos previos para llegar a la planta baja, con tantos planos fundamentales -calle, acceso, jardín, entrada, hall- que cuando llegamos no recordamos lo ascendido. 
13. Interior, entrada a sala de música, 1976. Autor: P. Vijdeveld (Cortesía archivo TUW)
14. Interior, escaleras hacia la planta superior, actual (Del autor).

15. Interior, entrada hacia el hall, actual (Del autor).

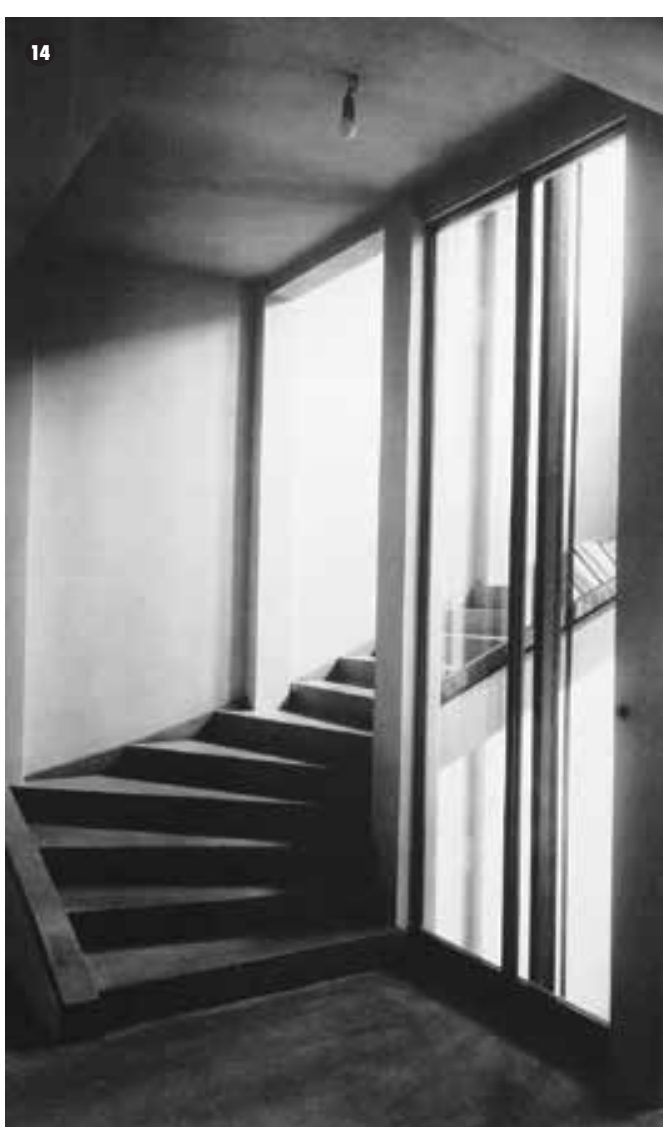

diferentes ámbitos, inestabilidad en la mirada, que intentando relacionar ámbitos interior y exterior, se yuxtaponen ambas posiciones por la referencia a varios horizontes visuales y conceptuales, inalcanzables como el origen de un arcoíris. Se aleja el horizonte que pone todo en común para expulsar el miedo de lo que no se puede palpar, pesada carga de la filosofía, simplificando la complejidad de lo real mediante una reducción formal de lo aglutinado por la mirada, al contrario que la fenêtre en longueur corbuseriana.

En ese expeditivo interior, la estructura se muestra y es interpretada geométricamente como normalizada aunque incorpora elementos novedosos, se realiza con una distribución estructural de pilares centrales y muros perimetrales en fachada, todos ellos de pie y medio de espesor, con vigas de acero remachado y perfilería metálica de acero en

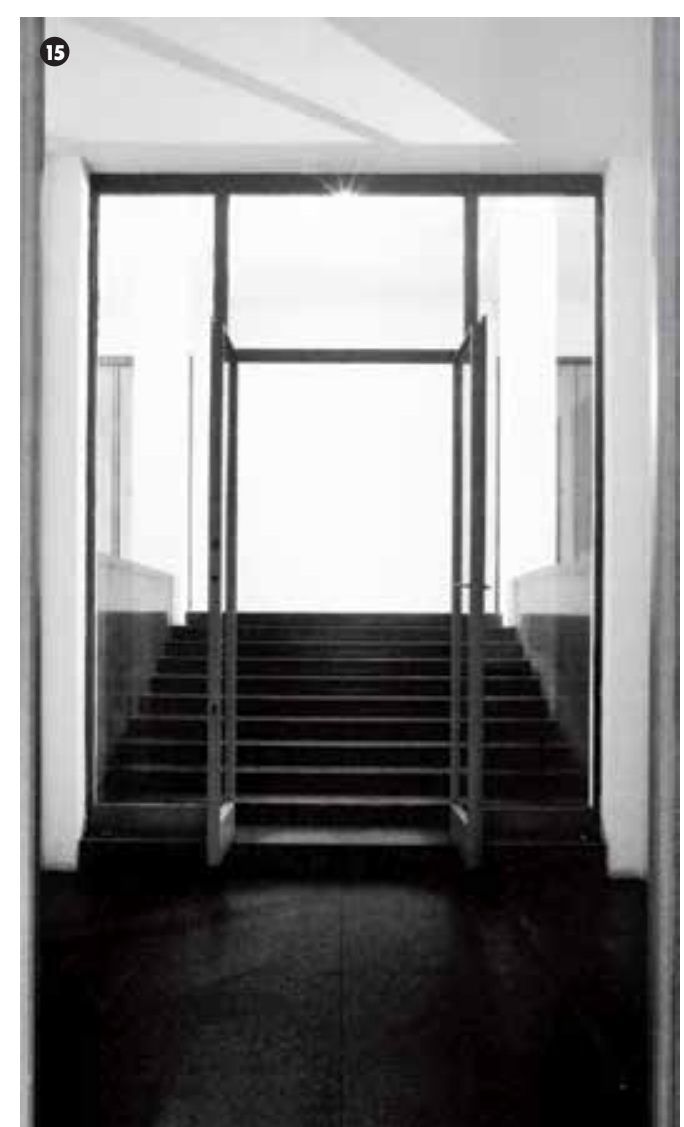

la subestructura interior, junto ascensor. No existen cámaras de aire, como era la costumbre de la época, intentando ser compensada la inhumanidad térmica mediante la distribución de calefacción por radiadores de fundición, un suelo radiante por aire en planta baja y confiando en los cerramientos. Pese a los evidentes desconocimientos constructivos que asaltan cualquier visita, la casa se encuentra repleta de accidentes aparentemente nimios que precisan de una experiencia atenta de los mismos. Posiciones y escala de puertas, vistas axiales y sus evoluciones mediante el movimiento, dimensiones asociadas a funciones con varios posibles usos... el vocabulario propio de este reduccionismo formal por el que se cubren los detalles de la conformación material, será ejecutado años más tarde por el arte abstracto y, posteriormente, por el minimalismo. Ningún elemento en sí tiene la apariencia de ser el resultado de un proceso analítico y sintético de de las plantas que, como en tantas otras ocasiones, parecen estar ubicadas aquí por una necesidad evidente, estando casi fuera del proyecto. 
ingeniería y posterior desarrollo industrial, sino que surge de un modo mucho más personal, por intuición y comprobación posterior del resultado inicial. Lo que hace Wittgenstein durante los dos años de obra, al desarrollar su proyecto de la casa y de la ciudad en este punto, es reducir la interpretación asociada a los elementos previamente grafiados. La estructura es solamente estructura, no aporta nada más real ni interpretativamente. Las cerrajerías, las escaleras. No hay envés complementario a la mirada.

La acción de Ludwig Wittgenstein al recoger el proyecto inicial es elevar el tono de lo que llega hasta él, empleando un tiempo mucho mayor en la atención a la concreción física y espacial de lo que Engelmann había plasmado en su proyecto. Wittgenstein había mostrado siempre un profundo interés en la eliminación de la profunda sensación de interioridad de sus arquitecturas vividas, todas ellas palaciegas; interiores que mediante una estructura compleja delimitan una concreción física del entorno opresor de la caverna inicial. Este anhelo de la exterioridad, antagonismo liberador de las estructuras rígidas personales y sociales de finales del XIX, es el trayecto de dicha interioridad hacia un exterior a menudo burdo y cruel, pero disponible para el viaje y la alegoría de la liberación personal. Este trayecto conceptual induce a Wittgenstein a provocar una radical reducción de los materiales usados y el ajuste dimensional para la coherencia interior y exterior, $y$ todo ello hace que el proceso de proyecto no sea el histórico - de ajustar un programa a un estilo preconcebido- sino de crear espacios para unas necesidades concretas, que, sin embargo, no son estancos sino interdependientes, conexos, complementarios en esa gran planta baja que parte de la crítica ha asimilado como único ámbito de la casa. Las otras dos plantas son un prodigio de incoherencia entre sistemas estructurales y de compartimentación y, de facto, la crítica en general no los describe sino desde su aporte a la escala global exterior del conjunto edilicio de volumen habitable+ plinto.

El ámbito vertical de la casa en todas sus plantas está conformado en la relación entre planta y altura según un preciso ajuste definido por Wittgenstein para cada ámbito. La escala es lo verdaderamente afectado por Wittgenstein sobre los esbozos de Engelmann al iniciar el proyecto de la casa. La casa, al menos no en su conjunto, no aparenta ser el resultado de una sucesión sintetizada desde un sistema previo de dimensiones -esto es, pensado en digital-, sino que se soluciona programáticamente según un sentido previo, localizado en cada enfoque diferencial que requiere el proyecto de arquitectura-operando en analógico-. En esta línea de trabajo, quizá el ejemplo más representativo sean las manivelas, que se colocan en toda la casa a $154,5 \mathrm{~cm}$ del suelo, por lo que están ubicados según la figura de la puerta presupuesta y no a una distancia normal de uso. Esto cambia por completo la escala del espacio. De hecho, todas las manivelas quedan por encima del hombro.

El interés por las proporciones de las salas ${ }^{[14]}$, la relación entre ellas y la disminución en las alturas era para Wittgenstein un asunto primordial, pues era la magnitud principal de transmutación desde el plano a la realidad; objeto mucho más significativo que la producción de detalles de cerrajería, aunque estos ocuparan mucho más tiempo de sus trabajo como arquitecto. El interés de este al incorporarse al proyecto no era solo un cambio en su trayectoria vital, sino demostrar la inexorabilidad de que el pensamiento aplicado, artístico y técnico, no consiste en determinados conocimientos artísticos o técnicos, sino en el hecho de que las proposiciones técnicas son también gramaticales. La certeza arquitectónica de que $2 m^{2}+2 m^{2}=4 m^{2}$ consiste en el hecho de que no lo utilizamos como una descripción, sino como una regla. Con esta adaptabilidad del proyecto previo a la realidad, se traiciona el orden previo autoimpuesto, y con ello la coherencia entre la noción conceptual, la representación y la realidad-que debiera ser la aportación que el TRACTATUS pudiera hacer al proyecto de arquitectura- es, sin embargo, traicionada por el filósofo, que juega a ser arquitecto y descubre que no puede acogerse a una metodología específica de trabajo racionalmente analítico y lineal, pues cualquier decisión pone de manifiesto las posibilidades del condicionante que estimaba esa última decisión como la más adecuada. El proyecto puede convertirse en un ciclo eterno de decisiones que provocan la desestabilización de los condicionantes que provocaron esa decisión. Respecto a cómo Wittgenstein decidía algunas de las proporciones de elementos, Heinrich Postl, un trabajador de la casa durante 50 años, relata cómo sorprendentemente Wittgenstein decidió la ubicación exacta de las barras horizontales que protege el interior de las ventanas del salón. Hizo mantener a dos operarios sosteniendo barra por barra desde un andamio dibujándolas desde el jardín y comprobando las proporciones de los espacios restantes desde el interior, hasta que tras varias horas, marcaron el lugar exacto. Este mecanismo determina la dimensión real de los elementos, que surge cuando se combina la relación que tamiza esa puertaventana, o esas puertas, con las inmediatamente cercanas y el alzado -interior o exterior- en el que se ubica. Bien lejos de aquel trasiego del grafismo a la realidad física que arrancaba el proceso de obra del palais. Tal vez este cuidado de la escala como medida en relación con las cosas a su alrededor es otro factor más que hizo girar la filosofía Wittgensteiniana de lo digital, exacto de su TRACTATUS, a sus INVESTIGACIONES FILOSÓFICAS, analógico, puestas ya en relación las partes y el conjunto:

[14] Uno de los caballos de batalla de Otl Aicher en sus artículos sobre la casa, en los que defiende su integridad formal frente a la visión que de ella había dado la crítica hasta los años '90. Hay todo un muestrario de alturas libres en la sección, que son variables en cada parte: la planta baja tiene entre 3,80 m y 4,00 m de alto, la planta primera entre 2,85 m y 3,05 m y la de los niños 2,80 m. La cota varía según se haga la medida al descuelgue de vigas -que toman una presencia constante en plantas baja y primera- o al propio tendido horizontal. Si consideramos el espacio limitado entre planos horizontales la secuencia sería 4,00 m; 3,05 m y 2,80 m para las plantas baja, primera y segunda, respectivamente. 

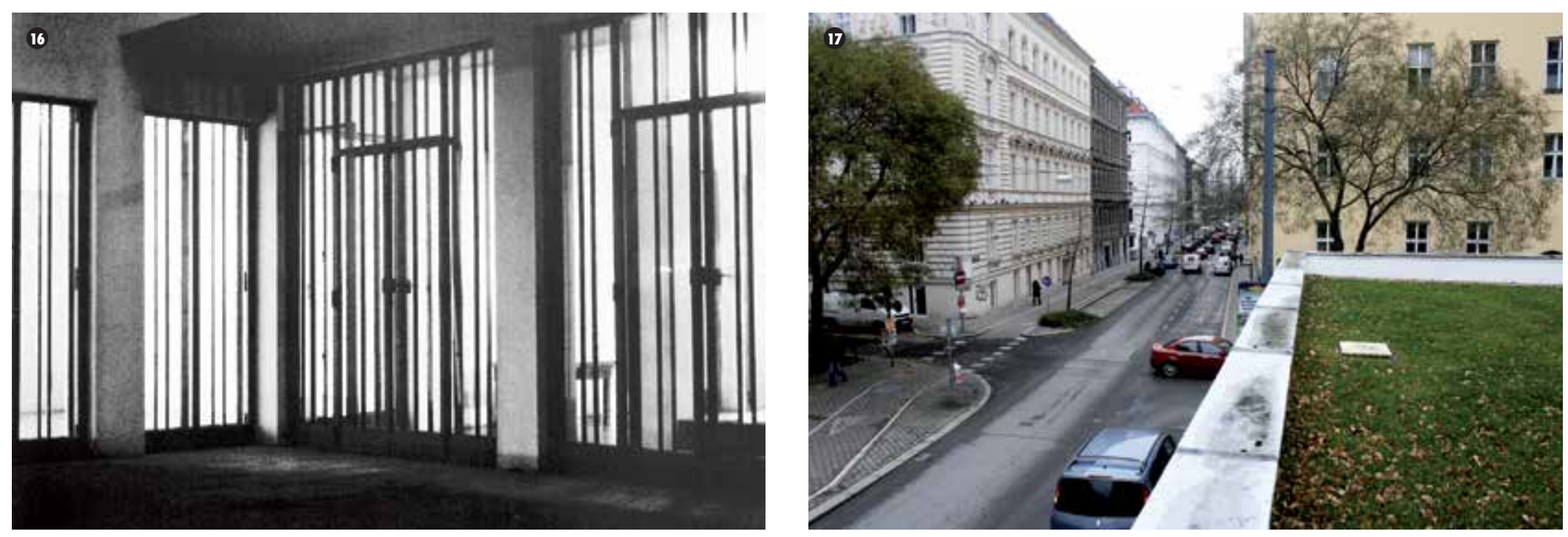

El secreto de dimensionar un sillón o la ventana de / una casa es que la percepción del objeto es cambiante. / Más allá de sí misma, aparece como continuación de esta parte, / ampliándola, aparenta ser una parte completamente autónoma. / Hazla más fuerte y parecerá que soporta algo más, / hazla más débil y parecerá depender de otra. / No hay una diferencia gradual (y cuantitativa) en la longitud que realmente importe, / excepto el aspecto cualitativo de la percepción ${ }^{[15]}$.

Esta proporcionalidad vertical según series continuas de dimensiones está íntimamente ligada con la monumentalidad aparencial, que se logra mediante la superposición simultánea de elementos conocidos figurativamente con una dimensión mucho mayor que la que tienen en usos domésticos equivalentes - por ejemplo, los pilares y pilastras son de 0,40 x 0,40; pero de 3,80 metros de altura y por ello más esbeltos de los acostumbrados, y las puerta ventanas ofrecen una sensación de dimensión mucho menor por la ubicación de los mecanismos de accionamiento, como ya se describe- nos descubre una escala que no corresponde en absoluto con la dimensión real. El orden estructural se convierte en uno de los principales medios de abstracción visual y material en la casa, pues la negación del capitel -o su reducción a un ábaco lineal que opera en la reducción del encuentro entre equino y arquitrabe, aunque bien pudiera ser este descuelgue entendido como el descuelgue testimonial de la clave a modo de acodo- y la ausencia de basa-incluso la presencia invertida del imoscapo, que se produce por un mínimo vaciado del arranque del pilar- es el rasgo primero de una estructura física que se muestra de forma parcial en la casa, mediante una sucesión de forzados descuelgues de vigas. El acuerdo que suponen estos centímetros de descuelgue, bien pudiera explicarse en la continuidad necesaria para la geometría del orden estructurado de la finalización de la columna jónica o corintia, en la que una mínima apófisis realizada mediante vaciado del calibre inicial del fuste enlaza este con la primera moldura del capitel o la basa. La negación en los extremos de la columna clásica produce la ilusión óptica que eleva la estructura al rango de motivo estructural representado más allá de la presencia del objeto que soporta el orden estructural. Esta estructura forzada en sus dimensiones, bien vigas bien grosores murarios regrosados, evita en los espacios la total abstracción que significaría un espacio paralelepipédico puro. Además, la abstracción es la que altera la escala perceptiva de todo.

La abstracción interior -que provoca un espacio de tiempo y función indeterminados- es, junto con la abstracción exterior -con ese guiño al entorno que supone la proporción vertical de los huecos y su repetición- un complejo contrapunto que implica cierta anulación de las categorías de interioridad versus exterioridad. Lo doméstico ha dejado de ser un interior contrapuesto a un exterior, sino que ya es un ser de dos caras, continuo, que tendrá que acomodarse y metamorfosearse en una membrana presionada por ambos lados; esa "piel» que nos separa del «mundo exterior y temible» de Loos $^{[16]}$ pasa a ser en la casa igual en el interior que en el exterior. Es una casa radicalmente desnuda en su interior y exterior, mineral, resistente, tal vez porque Wittgenstein intuía que en aquellas estancias la dureza de las relaciones sociales no sería más suave que en plena calle. Los muros están apretados entre la presión de la sociedad y el empuje de nuestra personalidad, que desean invalidarse mutuamente. Frente a ambas, la creación de los espacios interiores de

5] Del InVESTIGACIONES FILOSÓFICAS de 1951 (publicado 1953) de Ludwig Wittgenstein

[16] La arquitectura del modernismo establece en la diferencia entre el interior doméstico y el exterior amenazante la dicotomía fundamental del trabajo en superficie. 
la casa abiertos al jardín y proyectados como un telón de fondo para representar las relaciones sociales que justificaban el coste del proyecto; y que Wittgenstein en un intento de superar dicha visión totalitarista, funde interior y exterior asimilando sus materiales de acabado.

Estos acabados son similares en interior y exterior, con un revoco pétreo de diferentes proporciones pero similar composición: un revoco de cal en el exterior, protegida por un zócalo de color ligeramente más oscuro, de piedra artificial, en el arranque de los muros en el patio. Este exterior es de color blanco perlado, con una ligera textura raspada, y el interior posee un tacto similar; con solado de hormigón pulido, muy básico, pero con una cuasiperfecta distribución de juntas, particiones que resaltan la evidente modulación usada en las estancias y la imperfección de la misma por los accidentes provocados por la imposición de un sistema industrializado, con una mínima tolerancia adaptativa sobre un espacio de carácter artesanal con unas medidas que no vienen de la misma secuencia. Esta incongruencia en el ajuste entre realidad proyectada y realidad constructiva justifica que no haya anisotropía posible, sino una isotropía lineal con un marcado carácter clasicista. Dentro de los anillos superpuestos de cierre que son los murocerramientos solo se desarrolla una estructura de pilares de hormigón, novedosos, quizá por influencia de Loos y su más actualizado conocimiento constructivo. Esto hace que el espacio y las proporciones exactas no estén fijados por elementos estructurales, sino por el vacío que queda entre ellos. Un vacío disponible para la acción y el movimiento, movimiento del habitante que define los accidentes espaciales pretendidos en las estancias de la planta principal, en la que todas se abren al jardín directa o indirectamente.

Este efecto de continuo dejá vû -provocado por los capiteles negados, las ventanas y puertas de igual dimensión y ubicación, el mismo material en interior y exterior- se experimenta mientras recorremos una planta desarrollada en dos ejes transversales y que abren la casa al exterior, posibilitando la ilusión evidente de una aliteración infinita, que domina por completo la percepción de la planta baja, principal, de la casa. Este movimiento personal y escenográfico en el interior de la casa implica una continua composición geométrica del ojo, que activa la mirada en sucesivos enfoques al recorrer la planta baja: de una sala luminosa abierta al jardín pasamos al hall, profundo y que nos muestra levemente el acceso, distante. De ah hasta una sala cuya presencia se funde con la del jardín inevitablemente por la frontalidad de los grandes ventanales que hasta ahora se han presentado en exviaje, y al fondo la sala de música evidenciando de nuevo la entrada. Todo ese movimiento se combina con la neutralidad de paramentos, que permite la lectura escenográfica de los movimientos de los otros seres entre el espectador y los grandes lienzos casi blancos. Todos los materiales usados en la casa son artificiales o no naturales, Todos vienen como resultado de un costoso procesamiento industrial. Este marco conceptual es coherente con la exigencia de controlar todos los parámetros integrados en la arquitectura y el modo en el que se interrelacionan. Mies proyecta espacios nuevos, más allá del mero soporte de vida de la domesticidad, donde hombre y naturaleza cósmica se funden en una unidad trascendente de materia y pensamiento, mientras que Wittgenstein deseaba una coherencia entre materia y pensamiento, y acaba proyectando un soporte que pone en evidencia la vida detrás de la superficie.

Wittgenstein rechazó las alfombras, candelabros y cortinas, cualquier elemento añadido como decoración interior, al considerarlos incompatibles al ser meros añadidos al rigor de sus superficies neutras y sin significado. Los espacios pretendían estar acabados en sí mismos, y no necesitar más que de unos pocos muebles para facilitar su uso ${ }^{[17]}$. Esta fría monumentalidad rompe con una modernidad vienesa que no deseaba aún desprenderse completamente del ornamento, y provoca en la casa un vacío funcional que no pretende establecer relación unívoca entre edificio y función, abriendo al edificio a las posibilidades de uso que finalmente acogería. En la actualidad, el edificio se muestra completamente vacío, ofreciendo la visión de sus espacios sin aditamientos, lo que nos ofrece la posibilidad de analizarlo sin contaminaciones visuales de tipo alguno. Contra los edificios de la vanguardia del primer cuarto del siglo xx, desde Wright hasta Rietveld, en las que el mobiliario está realizado en consonancia con el resultado físico de las relaciones arquitectónicas para ser un complemento estético, la casa no es resultado de una relación forzada hacia una obra de arte tota|[18], en tanto que Wittgenstein está principalmente interesado en las respuestas que facilita el edificio, no los problemas que crea su cualidad espacial característica.

Esta arquitectura propuesta ${ }^{[19]}$ está tan vacía, tan disponible, que puede ser amueblada, habitada y representada con objetos antiguos o modernos, en tanto hagan justicia al interior propuesto por la eliminación de lo superfluo. Tan vacía y disponible a toda función queda -al menos, en planta baja- que no resulta clasicista en el sentido en el que la libertad de uso de la misma se fija respecto a un código formal de los espacios. La libertad está en el soporte, pues la vida interior se encuentra dentro de un sistema arquitectónico tan inexplicablemente neutro que no podía dejar de ser percibido. Las cualidades de la casa definen un marco físico híper-rígido en el que las actividades se realizan con la hiperflexibilidad propia de una adaptación posible a diversas funciones asociadas a espacios de dimensión no fijada para funciones concretas. Tal y como enunciaba Kazimir Malevich ${ }^{[20]}$, que pensaba en edificios como enormes y adaptables objetos para contener, dado que las necesidades humanas concretizadas en funciones son adaptables a

[17] No es una cultura japonesa, al fin y al cabo.

[18] Habríamos de recordar el intento de decorar la vida social y personal en el ensayo "pobre hombre rico» de Adolf Loos.

19] Ya podemos intuir que está radicalmente fuera del período estilístico al que temporalmente debería haberse plegado

[20] En MANIERISMO, ARQUITECTURA MOderna y OTROS EnSAYOS, Rowe, Colin. 
18. Interior, hall, actual (Del autor)

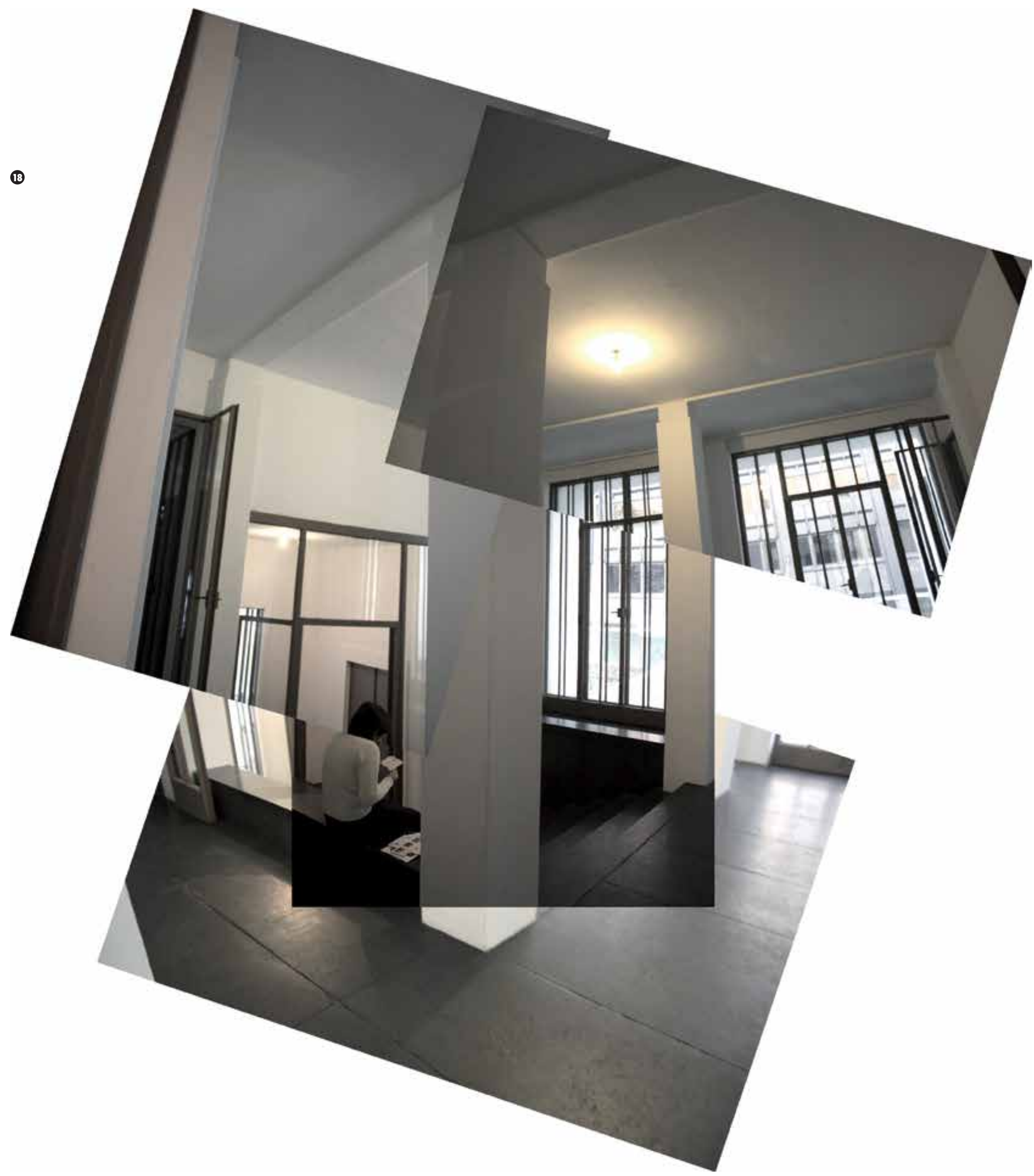


múltiples espacios. "Cuando el edificio denota la función a la que estaba destinado, es un edificio perdido». Dado que la arquitectura de la casa no es expresión de ningún mundo cultural o estético subyacente, sino que fue realizada ad hoc, no nos sorprende que su status de figura espacio-temporal no necesite de la referencia histórica para completarse. La arquitectura, en este caso, no dialoga con la historiografía de la arquitectura. Es muda, aunque existe la cita histórica. La referencia clásica de ciertos elementos como huecos y repetición de los mismos, verticales, no hace sino evidenciar aún con mayor fuerza su autonomía en este sentido.

Wittgenstein descubre en todo esto que el proyecto de arquitectura no estará fundamentado en la precisión y en la exactitud del trayecto del papel a la realidad, sino también en aprehender conexiones, relaciones y analogías, aunque todo ello se realice en el marco físico producto de una civilización técnica lineal y positivista, autoproyección del individuo moderno. Sin las acciones del habitar; las relaciones se objetualizan. Cuando Le Corbusier habla por primera vez del modulor en 1948, Wittgenstein hacía más de treinta años que había acabado su TRACTATUS; y estaba terminando el INVESTIGACIONES FILOSÓFICAS; en el que ya se afirma que la medida depende de la unidad que se utilice como referencia:

Y cuando sostengo el metro contra la mesa, / siempre mido la mesa. / ¿ No podría a veces estar comprobando el metro? [21].

Sin embargo, Le Corbusier comenzaba a principios de la década de los años 20 un camino universal ${ }^{[22]}$ para una humanidad no universal, y Wittgenstein, tras concluir la casa, realiza un profundo giro de su filosofía, y explicaba un hombre que es universal en cada acto mundano, y cuya universalidad radicaba ahí y no más allá. La casa trata de contener al

En Ludwig Wittgenstein, op. cit.

[22] Que sería la principal causa para sus posteriores detractores del Team $X$ y subsiguientes. humano mundano y universal, con dos espacios en cada estancia, al igual que el hombre es a la par universal y local. Construyendo la casa se supera el principio del TRACTATUS, pues el fenómeno interpretativo del habitar justifica la experiencia personal que lleva al filósofo hasta las consecuencias de su INVESTIGACIONES FILOSÓFICAS finalizado en 1949, un año más tarde de la publicación del MODULOR y cuatro años antes del MODULOR 2.

Proyectar será ya entonces, por tanto -para el filósofo que juega a arquitecto- una conformación intelectual, que mediante la clarificación de conexiones nos lleva a fijar las analogías, relaciones y campos relacionales que crean la globalidad compleja de un objeto arquitectónico o situación urbana, pero cuya bidireccionalidad de proceso fuerza a descubrir que se debe pasar del pensar al hacer, y en el hacer, comenzar de nuevo a pensar. Al habitarla, se presenta física y documentalmente un instrumento de investigación que un filósofo utiliza para plasmar el modo en el que una estructura particular puede contener en su configuración el germen de una verdad universal; pero cuyo complejo proceso de proyecto y obra acaba, al contrario, por enriquecer la percepción que de la realidad tenía Wittgenstein, y con este desplazamiento en su pensamiento nos facilita, aún hoy, e incremento de la riqueza de nuestro mirar. Este proyecto es uno de los pasos que hizo virar la filosofía estructuralista cartesiana del primer Wittgenstein del TRACTATUS (1918) a la riqueza perceptiva y experimental de Merleau-Ponty, Bachelard y el Wittgenstein del INVESTIGACIONES FILOSÓFICAS (1951).

Esta retroalimentación desestabiliza al pensador que separa ámbitos de realidad en contenedores impermeables, y descubre que el habitar no está solo fundamentado en la precisión y en la exactitud, sino también en aprehender conexiones, relaciones y analogías, aunque todo ello se realice en el marco físico producto de una civilización técnica lineal y positivista, fundada sobre la exactitud y la precisión. Sin las acciones de habitar; las relaciones se objetualizan. Este intento de desreferenciación del proyecto basado en la despersonalización de la figura mediante la conformación industrial tiene el efecto contrario, pues cuanto menor es la tolerancia al error industrial, más se necesita la utilización de la capacidad artesanal para la personalización concreta de una obra pretendidamente industrial, como ocurría entonces con los objetos de la Wiener Werkstate diseñados por Joseph Hofmann, que más tarde Walter Benjamin referiría en su triste la reproducibilidad de la obra de arte.

Esta es la sorprendente y catárquica secuela principal del proceso de proyecto y construcción de la casa de su hermana para Ludwig Wittgenstein: la experiencia de la conformación de una entidad física, ordenada por la acción artística y técnica, fuerza la apertura de su pensamiento hacia una posición exterior a los principios de la lógica y la razón pura, para seguir desde 1929 el camino del pensamiento que culminaría con la publicación de sus INVESTIGACIONES FILOSÓFICAS en 1953 y el inicio de la filosofía que haría evolucionar la modernidad hasta las bases filosóficas relativistas y experimentales en las que seguimos sumidos. Ludwig Wittgenstein, intenta hacer filosofía asumiendo el papel del arquitecto, y al proyectar un espacio ajustado a unas proporciones, con unas funciones determinadas y con unos materiales concretos descubre una estructura de toma de decisiones no lineal, biunívoca, alterable entre los extremos. En la realidad mental de Ludwig Wittgenstein, unívoca y lineal, positivista y rigidizada, se ejerce un esfuerzo micénico para levantar una estructura física plasmando una imagen de un sistema de pensamiento. Sin embargo, el espacio vivido, la luz, el jardín, descubren una multiplicidad de interpretaciones visuales y materiales, que deslimitan ese mismo sistema que intentaba plasmar, y abre así toda una nueva etapa a la filosofía del siglo xx. El cambio es evidente al comparar su obra antes y después de (entre otras concurrencias) la obra de la casa.

«La forma es la posibilidad de la estructura» (2.033)

TRACTATUS LOGICO PHILOSOPHICUS, 1918. 
19. Diferentes tipos de cerrajería interior, actual (Del autor).
20. Detalles de diseño interior, 1974. Autor: P. Vijdeveld (Cortesía archivo TUW).
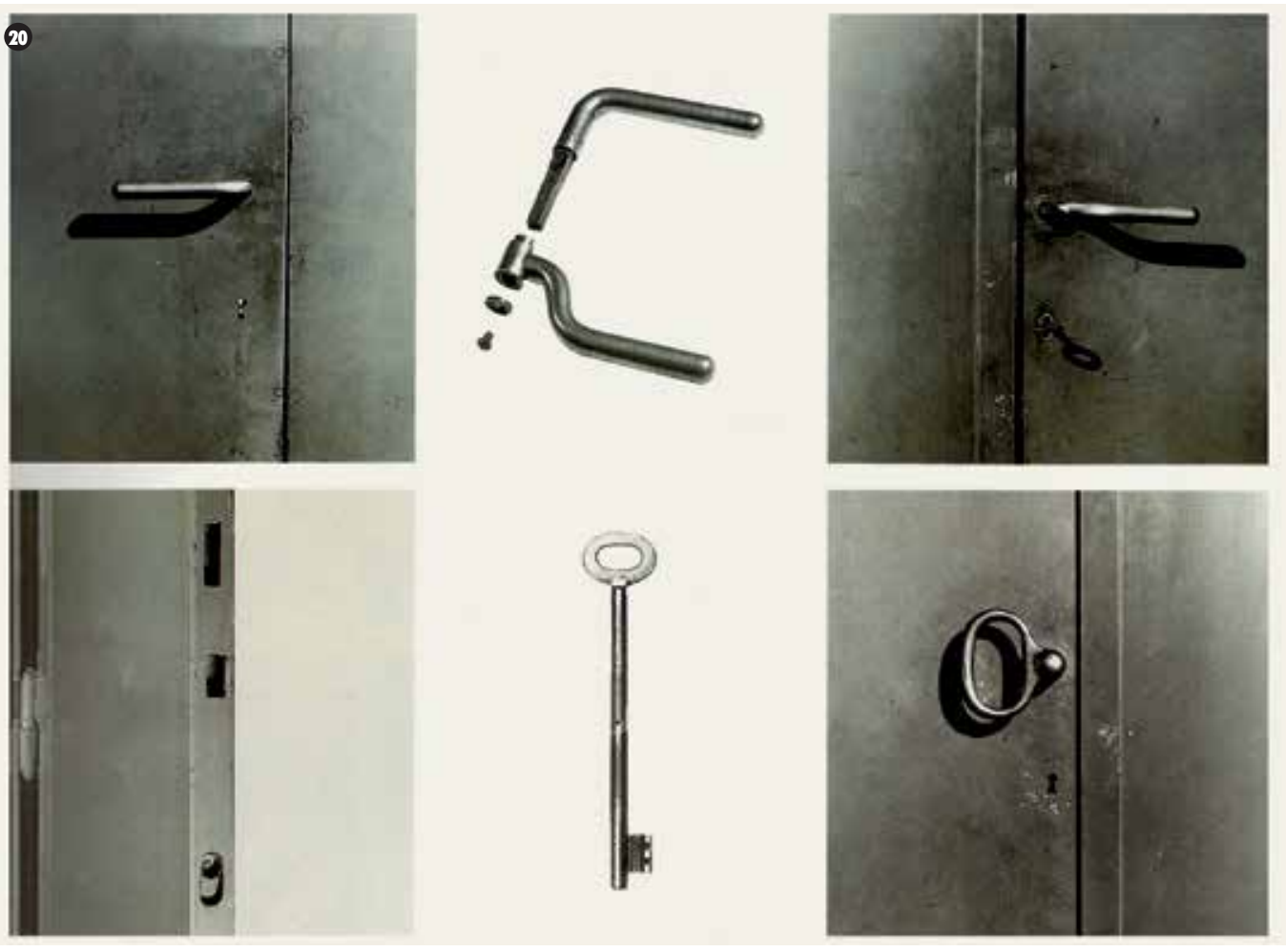

«Los objetos, sin embargo, sí pueden ser compuestos. / En los conjuntos de arquitectura, cada espacio, / concebido por separado, se integra de forma bilineal en el conjunto».

INVESTIGACIONES FILOSÓFICAS, 1949.

Cuando la casa es estudiada documentalmente en profundidad, se descubren textos inéditos que evidencian las contradicciones que descubren el hecho de que en realidad no es solo una arquitectura, sino un proyecto de filosofía realizado con técnicas de proyecto arquitectónico. Cuando la casa es descubierta contrasta con lo que hasta llegar a la misma opinamos de ella, una casa que al ser estudiada desvela un proceso de proyecto que, por complejo, es hoy más vigente que nunca; una casa cuya realización no es fruto del pragmatismo moderno aunque finja serlo. Hasta la modernidad, el proyecto de arquitectura era una actualización según el encargo de tipologías históricas e indiscutibles, fundada dicha actualización en diagramas de proporciones, pero aquí el proyecto se recrea como lenguaje en sí mismo -por su origen fuera de la historiografía-. Se libera a la arquitectura de la semántica, y se le ofrece un contenido. Sintomática del proyecto moderno de arquitectura es la primacía del saber práctico sobre el saber teórico; aunque la labor de Engelmann ha sido denostada por los filósofos como prescindible y, sin embargo, la gran cantidad de decisiones sobre la geometría original de la casa lo ha desmentido. La casa no puede sojuzgarse exclusivamente ni como arquitectura ni como filosofía, pues esta obra es una acción mixta de pensamiento y técnica en una tierra de nadie en la que la crítica, siempre posmoderna, ha accedido desde la profesión. Tanto la crítica severa, como la admiración mistificadora de la otra, lo hacen arquitectónicamente.

Aunque la valoración de las particularidades de cada situación de proyecto hoy es casi imposible por la falta de valores comunes a los que remitirnos -como acuerdo colectivo y convenido- para fundamentar el grado de acierto de un proyecto es evidente, los procesos creativos refrendados después a nivel técnico y visual desde herramientas de CAD han generado un nuevo valor común a la acción proyectiva global; dotando a la praxis del proyecto de una entidad dogmática cuya coincidencia de expresión sí conforma una base común al trabajo de gran parte de los arquitectos. No pensamos todos de la misma forma, pero sí trabajamos todos -casi-del mismo modo, principalmente por la similitud de las herramientas de trabajo. Los actuales medios de expresión para la concreción de la proyección arquitectónica y artística amplían los límites del pensamiento, pues ellos posibilitan una representación simultánea del estado actual y el posterior proyectado, construyendo a la par interpretación y descripción del mundo externo que se presentaba tradicionalmente a modo de realidades diferenciadas.

Para la crítica ha sido imposible encontrar un nicho de clasificación para el palais 
entre el expresionismo, la modernidad y la fenomenología posmoderna, pues puede estar presente en todos aunque no es imprescindible en ninguno. Es tan intemporal que ocupa varios tiempos a la vez, y por sí, ninguno; es una de las capacidades que la hacen ser propositiva ahora, en el tiempo de la desclasificación y la globalización extensa. El brusco desplazamiento en las condiciones laborales de los arquitectos durante el último lustro ha provocado la desaparición del delineante, figura entre el arquitecto anteriormente desbordado de trabajo- y la representación de la realidad proyectiva. La separación entre proyectar y dibujar se hace imperceptible en unos estudios mayoritariamente conformados por arquitectos que proyectan y dibujan en un único movimiento, delante del medio informático, desplazando el dibujo asistido por ordenador (CAD) por programas de proyección real (Software RPS). Esta producción segregada, alejada muchas veces del pie de la obra, permite el trabajo de los arquitectos específicamente sobre proyectos de arquitectura, reduciendo las variables de producción de la obra de arquitectura hasta el punto de variables geométricas y gráficas, y con ello facilitando la homogeneización de un modo de trabajo que a partir de la segunda mitad del siglo XIX podía llegar a considerarse verdaderamente internacional, y ahora más que en ningún otro momento. Desde TALESIN y hasta el Ateller de Van de Velde, en los estudios se produce arquitectura reflejada y literal. Desde Le Corbusier, la arquitectura se genera para lugares y condiciones muy lejanos, modo de producción que la red hoy posibilita con una facilidad suma. En la actualidad, la profesión se encuentra sin consenso sobre la noción de calidad arquitectónica, y aunque es reconocible por parámetros obvios, queda diluida en el ambiente multipolar que, con múltiples orientaciones, nos hace navegar con varios rumbos e intercambiables. Al no tener todos la misma referencia en igual Norte, el juicio de valor es múltiple para cada demora.
En tormenta parecida trimaba Wittgenstein, y decidía fijar su Norte en el espíritu íntegro que es la certeza interior de que la calidad está en la integridad de la propia obra, y solo en el objeto de proyecto descubre que puede surgir la coherencia íntegra, pues el lenguaje se transmuta desde el objeto existente producto de un pensamiento activador. En una época que intenta tratar a los arquitectos como figuras prescindibles pero legalmente ineludibles, el empeño personal de Wittgenstein es inspiración de resistencia personal por cuanto esa búsqueda de la perfección demuestra está en la propia obra, en su orden interno, su compacidad y corpus generado, además de solucionar problemas sociales o responder a demandas económicas. No por resolver problemas un edificio es bueno. La calidad de la obra viene de la intensidad de la acción, que como categoría aristotélica se encuentra íntimamente vinculada a la pasión como recipiente emocional subjetivo de la modificación material objetiva que es la acción de proyectar.

¿̇Es menos real una arquitectura no edificada que una edificada, cuyo significado supera con creces el significante real? La ratio entre obras proyectadas y obras edificadas desciende en los estudios de arquitectura in crescendo por la disminución de trabajo y el aumento desaforado de nuevos profesionales. Los proyectos son cada vez -tanto en número como en calidad- más gráficos que reales, pero el proyecto redactado como corpus edificado en el papel es tan real como la más construida de las arquitecturas; incluso está más cualificado para soportar el paso del tiempo y la ausencia física de los proyectos que alguna vez existieron y dejaron de ser físicos. Hay dos principios de proyecto fundamentales que caracteriza la casa: el proyectar como proceso y el proyecto como composición de una apariencia en tanto que forma física objetual. Ambos nos inspiran a construir el proyecto más allá de la materialidad. Es por ello que el palais Wittgenstein, contra lo que de él se ha dicho en pro y en contra, es autónomo pero sensible, vacío pero pleno, nihilista pero sensual; y gracias a los contrasentidos que aglutina el proceso y la casa resultante, el individuo positivista de la modernidad-convencido de la unicidad de la relación entre significado y significante, autoformado para la felicidad social y que justifica las acciones actuales en el día de mañana-conforma una casa que no es solo un proyecto de arquitectura, sino un instrumento de investigación que enriquece la percepción que de la realidad se tenía, y con este desplazamiento en su pensamiento nos facilita, aún hoy, el incremento de la riqueza de nuestro mirar. Sorprende pensar, por todo esto, que una sencilla casa pueda ser uno de los motores del cambio en el curso de la humanidad, pero en esta posibilidad última fundamos los esfuerzos y las múltiples decisiones de los proyectos nuestros de cada día. Aunque sean reconocidos cincuenta años tarde, como le ocurrió al palais.

\section{REFERENCIAS BIBLIOGRÁFICAS}

Aicher, $\bigcirc$. Analógico y digital. Traducción de Yves Zimmermann. Barcelona: Gustavo Gili, 2001.

Aicher, O. El mundo como proyecto. Traducción de e Inge Aicher-Scholl. Barcelona: Gustavo Gili, 1994

Baudrillard, J. El sistema de objetos. Madrid: Siglo XXI, 1969.

Bernard, M. «Les mecenes de la secession». Catálogo de la muestra Vienne. L'apocalypse joyeuse. París: Centro Pompidou, 1986.

Broch, H. Die Schlafwandler (Los sonámbulos). Barcelona: Lumen, 1986.

Engelmann, P. Ludwig Wittgenstein. Tel Aviv: Engelmann, 1948.

Wittgenstein, H. Escritos de familia. Viena: Verlag, 1996.

Wittgenstein, L. Tractatus logico philosphicus. Madrid: Alianza Editorial, 2003.

Wittgenstein, L. Investigaciones filosóficas. BarcelonaMéxico: Crítica, UNAM, 1988 